\title{
A Framework for Assessment for Learning: Implications for Feedback Practices within and beyond the Gap
}

\author{
Kelvin Tan \\ Curriculum, Teaching and Learning Academic Group, National Institute of Education, 1 Nanyang Walk, Singapore 637616 \\ Correspondence should be addressed to Kelvin Tan; kelvin.tan@nie.edu.sg \\ Received 14 February 2013; Accepted 12 March 2013 \\ Academic Editors: B. Marlow, R. Martens, and S. Thoma \\ Copyright (C) 2013 Kelvin Tan. This is an open access article distributed under the Creative Commons Attribution License, which \\ permits unrestricted use, distribution, and reproduction in any medium, provided the original work is properly cited.

\begin{abstract}
Three recurring emphases in the literature on formative assessment are (a) the importance of assessment design in prompting and sustaining students' learning, (b) giving students feedback that enables them to improve their work, and (c) clarity of standards to articulate the gap between past and desired performances. Much has been written on how each of these is important in designing and using assessment for learning. But there is considerably less attention (if any) on how these emphases should confluence each other. In this paper, I propose a framework for assessment for learning (AfL) wherein assessment standards (vertical axis), task design (horizontal axis) and feedback practices (incline) form a "triangle of practices" that construct the "space" for enhancing learning. Implications for formative assessment to extend learning beyond its triangulated frame are discussed.
\end{abstract}

\section{Introduction}

Black and Wiliam's [1] comprehensive review of formative assessment research has been relied on by many to argue that formative assessment has significant benefits for enhancing students' learning. In that study, the authors framed formative assessment (very) broadly to be interpreted as "encompassing all those activities undertaken by teachers, and/or by their students, which provide information to be used as feedback to modify the teaching and learning activities in which they are engaged." (Page 7). Such a broad notion of formative assessment included diverse practices such as selfassessment, learning goals, and mastery learning. This casts doubts on whether it is possible to precisely determine the specific "formative assessment practice" for which the gains in performance could have been attributed to.

Bennett [2] argues forcefully:

a major concern with the original Black and Wiliam [1] review is that the research covered is too disparate to be summarised meaningfully through meta-analysis. That research includes studies related to feedback, student goal orientation, self-perception, peer assessment, selfassessment, teacher choice of assessment task, teacher questioning behaviour, teacher use of tests, and mastery learning systems. That collection is simply too diverse to be sensibly combined and summarised by a single, mean effect-size statistic (or range of mean statistics). (Page 11).

The ambiguity over what is exactly and minimally needed for formative assessment to succeed is not confined to Black and Williams [1]. Shepard [3] produced a comprehensive model of formative assessment which lists ten key characteristics of formative assessment of which Cizek [4] has observed that "not all of the characteristics must be present for an assessment to be formative" (Page 7) and that not all the characteristics have to be combined or utilised in any application of formative assessment. It is clear that the bountiful literature on formative assessment, and its related areas of feedback practices and assessment design, would have much to recommend for classroom and assessment practice. But it is less clear which practices in particular are minimally required in order for formative assessment to succeed. This paper attempts to identify the minimal requirements for formative assessment to succeed in terms of assessment standards, assessment design, and assessment feedback. 


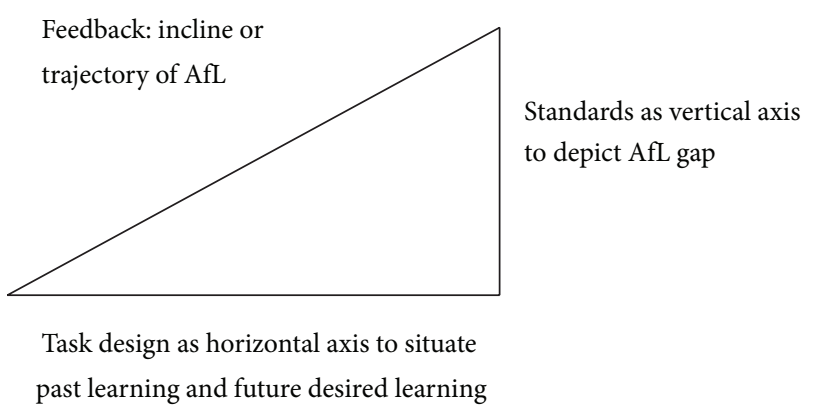

FIgURE 1: Triangulated model of assessment for learning.

Three recurring emphases in the literature on assessment for enhancing learning are (a) clarity in illuminating standards that may articulate the gap between what was achieved and what can be gained, (b) the importance of assessment design in prompting and sustaining students' desired learning, and (c) giving students feedback that enables them to improve their learning (see Figure 1). Much has been written on how each of these is important in designing and using assessment for learning. In this paper, I argue that assessment design, student feedback practices and clarity of standards are three components of assessment for learning that influence and construct each other. A model for framing assessment design, feedback, and standards is proposed.

1.1. Framing Assessment for Learning (AfL) as Standards, Design, and Feedback. It is argued that assessment standards, design, and feedback should be understood as triangulating the proximal space in which assessment activities may enhance students' learning within a distinct period of time, and that these three elements broadly constitute minimal requirements for AfL to succeed. These three elements need to be understood in relation to each other, and together they triangulate distinct contexts for assessment to be understood and used for enhancing students' learning as depicted in the following diagram.

The element of standards depicts the vertical axis of the triangulated model of AfL by articulating the possible and targeted gaps that assessment practices seek to close for each student. The element of task design depicts the horizontal axis of the triangulated model of AfL by setting out the assessment tasks which sequence and pace when learning is first ascertained and when it is subsequently assessed in order to determine if students' learning had improved as planned. The element of feedback depicts the incline or trajectory of the triangulated model of AfL. The level of incline conveys how ambitious the feedback seeks to be. For example, if the gap (vertical axis) is very wide and the time between assessment tasks (horizontal axis) is short, then the nature of student feedback would have to be rather ambitious.

1.2. The Minimal Need for Standards in AfL. Black et al. [5] explain assessment for learning to be "any assessment for which the first priority in its design and practice is to serve the purpose of pupils' learning” (Page 2). A popular assertion of formative assessment is that an assessment is considered to be formative only to the extent to which its use improves student outcomes [6]. The obvious implication is that formative assessment should not merely generate useful information for teachers and students. In addition, the resulting information should also be used by students in ways that enhance their learning outcomes. This presumes two other things: (1) That the enhanced learning outcome, or improvement in performance/scores, is significant enough to be recognized and (2) that there are clarity and certainty of standards to ascertain whether there has been any improvement in learning. This is not a new idea. For more than two decades (see [7]), Royce Sadler has been arguing that teachers and students need to ascertain the gap between current and desired performance levels that is bridged by formative assessment practices. Likewise, Buckles et al. [8] argue that clear descriptions of standards of performance are important for informing students what they are expected to learn and how they should perform in their assessed work, and for informing teachers how they can assess students accordingly.

1.3. The Minimal Need for Feedback Premised on Standards in AfL. A common and popular version of feedback theory is Ramaprasad's [9] definition that "Feedback is information about the gap between the actual level and the reference level of a system parameter which is used to alter the gap in some way" (Page 4). Sadler [7] lists three essential conditions for student feedback to be effective.

(i) Students must understand what good performance is (i.e., the student must possess a concept of standard being aimed for).

(ii) Students must understand how current performance relates to good performance (for this, the students are able to compare current and good performance).

(iii) Students should understand how to act to close the gap between current and good performance.

What Ramaprasad's [9] definition and Sadler's [7] conditions for feedback have in common is the need for clear standards of learning to be articulated in order to identify a student's gap in learning that feedback may address. In common discourse, standards are whether a programme of study or examination results show a level of satisfaction/achievement. But in terms of functioning as a yardstick for gauging whether learning or enhancement of learning has actually taken place, standards need to be more unambiguously defined before tests and examinations.

1.4. The Minimal Need for Assessment Design for Feedback to Bridge the Gap. The only way to tell if learning results from feedback is for students to make some kind of response to complete the feedback loop [7]. Likewise, Boud [10] argues strongly that "unless feedback is applied and used to demonstrate improvement, there is no way to tell if it has been effective" (Page 10). This implies a few things: (a) students were given a task from which useful feedback could 
be given, (b) there is a subsequent task for which students may apply the feedback to, and (c) The feedback is suitable for assisting students to improve their learning towards a desired (referent) standard.

These have implications for how assessment tasks are designed, as well as post-assessment task activities for students to benefit from using the feedback.

The targeted ambition of students' enhanced learning in AfL depends on the opportunities for students to receive and act on feedback. This is premised on there being assessment tasks that prompt the initial learning, and a subsequent task that permits the student to apply feedback on their learning. As Sadler [7] has argued, students need more than information on what is, and how to close, the gap between their current and desired performance levels-they require opportunities to use teachers' feedback.

The emphasis on students being to use, and not just understand, teachers' feedback in subsequent assessment tasks has received considerable recent attention. Orsmond et al. [11] observe the current expansion of research on feedback to "consider not only methods by which tutors may enhance their feedback practices, but has also began to consider students perceptions of feedback and their use (emphasis mine) of feedback" (Page 5). Likewise, Hounsell et al. [12] and Scoles et al. [13] emphasize the value of feedback to students as focusing on what the students can do (or aim to do) with the feedback in their next or future assignments. Such an emphasis is known and labeled by some as "feedforward" - the notion of effective learning from feedback whereby teacher's feedback is utilised by the students to inform their efforts in future assessments.

In Tan [14], it was suggested that such a systematic approach to ensuring a coherent series of assessment tasks that could prompt feedback and also provide subsequent contexts for applying feedback would include the following characteristics.

(i) It should recognise that students learn over a period of time. Hence, assessment design may comprises a serie of assessment tasks over time that serves the twin purposes of producing feedback and affording suitable and imminent opportunities for students to utilise the feedback.

(ii) The series of tasks should be coherent in order to progressively integrate students learning. The tasks should be relevant to each other so that feedback on a single task may enhance students' learning in a subsequent task.

(iii) Whilst each task should result in a distinct assessment outcome, the accumulative effect of the series of tasks should connect these outcomes into a final integrative outcome. The final integrative assessment outcome should be more than an aggregate of all its preceding and accumulative outcomes, and it may also act as a "final" context for students to understand and apply all prior feedback against.

An example of such an assessment design is the patchwork assessment method $[15,16]$. The patchwork text is claimed by Winter [17] to "integrate the different assessment advantages of the essay and the portfolio" (Page 119). First published in a special dedicated issue of the journal "Innovations in Education and Teaching International" in 2003, the patchwork text provides an assessment structure that places a premium on students constructing and synthesizing their knowledge. Ovens [18] refers to the patchwork text as "a form of assessment where students write several short pieces, the "patches," at intervals throughout the module and then at the end, the patches are "stitched together" to make a patchwork text" (Page 546).

Typically, the patchwork text assessment method entails a series of tasks for students to complete over a period of time and culminates in a final task that requires them to synthesize what they had learned in the previous tasks. Further examples of patchwork assessment in schools may be found in Tan [19] and Tan and Koh [20].

\section{Discussion}

The framing of formative assessment delimits what assessment is precisely able to do for learning. The potential of formative assessment to enhance learning is thus limited by 2 main factors: firstly, by the amount of time in which formative assessment is practised (horizontal axis of the formative assessment triangle), and secondly the realistic gap in students' learning that may be bridged within that time (vertical axis of the formative assessment triangle). These limitations in turn pose questions as to whether formative assessment is able to enhance learning beyond the immediate/imminent context.

Formative assessment is said to enhance learning, but it is not always clear whether such enhanced learning refers to the immediate learning that arises from feedback on a specific assessment task, or to longer-term learning beyond a programme of study. I argue that formative assessment practice is typically oriented towards enhancing short-term learning and is therefore not naturally suited towards sustaining learning for the long term.

Vardis [21] argues that students usually would attend to most teachers' written feedback if the feedback is specific to the students' written work, and if they are given the opportunity to revise their work. This requires students to be provided suitable post-assessment opportunities to apply given feedback. And these opportunities should take place soon enough after the feedback is given.

Such an emphasis on imminent applied contexts for students to utilise feedback focuses the utility of formative assessment on learning in the short-term-learning (or enhanced learning) that is envisaged in a subsequent assessment task/context.

In the short-term, formative assessment practices require students to understand assessment standards in order to act on teachers' feedback. Students require ability to judge their own learning in order to benefit from formative assessment practices. Such self-assessment by students focuses on the formative potential of the present assessment task, but does not necessarily develop nor sustain their ability for their own 
future learning needs. Boud [10] had identified formative assessment practices to be vital to achieving sustainable assessment but observed that discussion of formative assessment in the literature and in practice "has made relatively little contribution to current assessment thinking" and that "new thinking is therefore required to build sustainable assessment" (Page 159).

Sustainable assessment may be understood as "assessment that meets the needs of the present without compromising the ability of students to meet their own future learning needs" [10]. In this context, assessment has to enhance learning beyond its immediate formative context of the program of study. When designing assessment for student learning, we should also be mindful of the sustainability of the kinds of learning that the assessment seeks to enhance. Yet, it is rare to be able to identify assessment practices that are able to sustain students' learning beyond an academic level, let alone beyond a period of formal education. Current assessment practices tend to fix students' attention only on the next high-stakes assessment event without any thought for their learning beyond that summative testing episode. It is submitted that current discourses of formative assessment are not designed, nor intended, to enhance (or extend) students' learning beyond imminent summative assessment contexts, let alone long-term learning beyond a course of study.

Formative assessment that is sustainable should therefore enhance students' capacity for long-term learning beyond the context of immediate assessment practices. My position is that a different conception and practice of formative assessment to sustain long-term learning beyond immediate assessment tasks is required. It would require formative assessment opportunities for students to learn how to address issues of power in assessment practices, identify and assert their own constructed standards and criteria, and argue for the acceptance of their judgments in relations to others. Such formative assessment practices in turn require a high degree of student involvement and engagement in assessment practices. This requires increasing both the instances of student self-assessment activity, as well as a progressive effort to improve students' self-assessment ability.

Self-assessment is important for students to realise the immediate potential benefit of formative assessment feedback. But sustainable formative assessment is also important to ensure that students' self-assessment ability enables them to identify, protect, and assert their own judgements of learning and identification of long-term learning needs.

2.1. Learning beyond the Gap: The Threshold of Assessment for Learning. In order for assessment to enhance imminent learning and safeguard students' capacity for future learning, there will need to be a different kind of assessment for learning paradigm. The notion of a threshold has promising potential in this regard.

What formative assessment feedback attempts to do is to provide students with immediate or short-term improvement after each assessment task. Such formative assessment practices typically focus on enhancing students' learning at fixed points in time and are constrained by the scope and limitations of the assessment tasks. However, there may be areas of "improvement" over a period of time that is beyond feedback given in separate instances of assessment. Such a level of improvement may be conceptualised as a threshold level, that is, a level which is beyond a learner's current identified potential. Failure to surpass a threshold may result in students perennially being limited to lesser and lesser gaps for improvement and potentially creating a glass ceiling that traps students within a level of achievement or standard.

A threshold would be a kind of significant standard that would define a completely new level of proficiency [22]. Not every new level or incremental improvement would automatically be a threshold. One way to understand this is to consider the difference between a standard and a threshold. A standard may be understood as "a definite level of excellence or attainment, or a definite degree of any quality which is recognised as being adequate for some purpose by authority or custom." So if a student improves an essay from a $\mathrm{C}$ grade to a $\mathrm{B}$ grade, which would be an improvement in his standard, it may not amount to a threshold.

The notion of a transformative threshold is akin to that of a threshold concept. Meyer and Land [23] coined the term "threshold" as a metaphor to describe a certain level of learning gain such that passing through this threshold (portal) means that the learner acquires transformed capabilities in conceptualisation. Surpassing such a threshold thus represents a gateway for the learner to understand the accompanying concepts and theories. Likewise, Davies and Brant [24] describe a threshold concept as presenting levels of understanding in a subject (or activity) that I argue can be used in envisioning what assessment for learning should be able to do for learners.

Three attributes of threshold concepts are suggested by Meyer and Land [23], and I will use these attributes to expound on what it would mean for students to identify a threshold of learning as a means to go beyond the formative feedback gap limitation.

Firstly, a threshold level of assessment for learning needs to be irreversible so that new perceptions and understandings of what assessment should do for learning will not be reversed. Huge parental interests and anxiety in students' future careers often hinge what students' academic results in national examinations. Parents, as stakeholders, are not necessarily interested in utilising assessment to enhance their children's learning. They would be far more concerned about whether assessment or assessment for learning practices would jeopardise their children's academic results in any way. A new threshold of assessment for learning should be directed towards achieving the present and future learning needs of students in ways that cannot be reversed or undermined by resistant parents.

Secondly, just as assessment should not atomise learning which is hitherto holistic and integrated, a threshold of assessment for learning should also be coherent and integrative. Reformed assessment changes should seek to cohere assessment practices in schools. Just as learning and the curriculum should be holistic and understood in relation to its constituent parts, assessment for learning practices should 
be designed and practised as an integrative whole to preserve the integrity of students' learning. This would go a long way towards preventing the atomising of curriculum through assessment modularisation.

Thirdly, a threshold of assessment for learning in schools can be valuable as a catalyst for transforming the direction and value of education. To reframe assessment as if learning were important, it is critical to recognise that assessment is bounded by, and therefore can act as, the pivot for different forms of learning and understanding that a holistic education can bring about. Education in many countries is viewed as essentially pragmatic, and assessment is seen as the most direct opportunity to secure sought-after school places and stable lucrative careers. A new threshold of understanding and using assessment that is directed at emphasising the epistemological richness of learning different subjects and disciplines would instead redirect assessment outcomes from its regulatory features towards emphasising its learning features [25].

An assessment for learning threshold will be potentially troublesome in raising new perceptions that may be quite unfamiliar and of concern to educators. A well-regarded education system will find it hard to admit to areas for improvement, even if it implicitly does so by an unrelenting pursuit for continuous progress. However, the rhetoric of continual steady progress may sometimes disguise troubling issues which act against the direct interests of some students.

A threshold level of assessment for learning would help to bring about a greater level of confidence, perhaps to a sufficient level of reassurance that would permit the school leaders and teachers to publicly admit to troublesome issues to address in and through assessment practices. Just as formative assessment seeks to bridge the gap between present and desired levels of learning, a threshold of assessment reform can articulate the gap between the troublesome issues that plague assessment practices in schools and the desired levels of irreversible, pivotal and integrative learning that a country and its learners may aspire to.

\section{Conclusion}

In this paper, I have argued for assessment design, student feedback practices, and clarity of standards to be understood as a coherent set of assessment practices in relation to each other. A triangulated model for framing assessment design, feedback, and standards is proposed wherein assessment standards (vertical axis), task design (horizontal axis), and feedback practices (incline) form a "triangle of practices."

The element of standards depicts the vertical axis by articulating the possible and targeted gaps that formative assessment practices seek to close for each student. The element of task design depicts the horizontal axis by setting out the assessment tasks which sequence and pace when learning is first ascertained, and when it is subsequently assessed in order to determine if students' learning had improved as planned. The element of feedback depicts the incline or trajectory. The level of incline conveys how ambitious the feedback seeks to be. An effective feedback practice depends on clarity of standards to depict the gap and design of assessment tasks for students to act on feedback.

The framing of assessment and learning offers a concrete and explicit way of explaining the distinct roles of assessment design, standards, and feedback. It also articulates the confluence of design, standards and feedback and offers a coherent approach to assessment for learning that both teachers and students can understand and use in dialogue together. Such dialogue is important for sustaining students' learning beyond imminent contexts and should support students in identifying and surpassing their own threshold(s) of learning.

\section{References}

[1] P. Black and D. William, "Assessment and classroom learning," Assessment in Education, vol. 5, no. 1, pp. 7-74, 1998.

[2] R. E. Bennett, "Formative assessment: a critical review," Assessment in Education, vol. 18, no. 1, pp. 5-25, 2011.

[3] L. Shepard, "Classroom assessment," in Educational Measurement, R. L. Brennan, Ed., Praeger, Westport, Conn, USA, 4th edition, 2006.

[4] G. Cizek, "An introduction to formative assessment," in Handbook of Formative Assessment, H. Andrade and G. Cizek, Eds., Routledge, New York, NY, USA, 2010.

[5] P. Black, C. Harrison, C. Lee, B. Marshall, and D. Wiliam, Assessment For Learning: Putting It Into Practice, Open University Press, Berkshire, UK, 2003.

[6] D. Wiliam, "An integrative summary of the research literature and implications for a new theory of formative assessment," in Handbook of Formative Assessment, H. Andrade and G. Cizek, Eds., Routledge, New York, NY, USA, 2010.

[7] D. R. Sadler, "Formative assessment and the design of instructional systems," Instructional Science, vol. 18, no. 2, pp. 119-144, 1989.

[8] S. Buckles, M. Schug, and M. Watts, "A national survey of state assessment practices in the social studies," The Social Studies, vol. 92, no. 4, pp. 141-1146, 2001.

[9] A. Ramaprasad, "On the definition of feedback," Behavioural Science, vol. 28, no. 1, pp. 4-13, 1983.

[10] D. Boud, "Sustainable assessment: rethinking assessment for the learning society," Studies in Higher Education, vol. 22, no. 2, pp. $151-167,2000$.

[11] P. Orsmond, S. Maw, J. Park, S. Gomez, and A. Crook, "Moving feedback forward: theory to practice," Assessment \& Evaluation in Higher Education, pp. 1-3, 2011.

[12] D. Hounsell, V. McCune, J. Hounsell, and J. Litjens, "The quality of guidance and feedback to students," Higher Education Research \& Development, vol. 27, no. 1, pp. 55-567, 2008.

[13] J. Scoles, M. Huxham, and J. McArthur, "No longer exempt from good practice: using exemplars to close the feedback gap for exams," Assessment \& Evaluation in Higher Education, 2012.

[14] K. Tan, "Assessment for learning in Singapore: unpacking its meanings and identifying some areas for improvement," Educational Research for Policy and Practice, vol. 10, no. 2, pp. 91-103, 2011.

[15] J. Akister, "Designing and using a patchwork text to assess social work students undertaking a module in family therapy," Innovations in Education and Teaching International, vol. 40, no. 2, pp. 202-209, 2003. 
[16] R. Dalrymple and P. Smith, "The patchwork text: enabling discursive writing and reflective practice on a foundation module in work-based learning," Innovations in Education and Teaching International, vol. 45, no. 1, pp. 47-54, 2008.

[17] R. Winter, "Contextualizing the patchwork text: addressing problems of coursework assessment in higher education," Innovations in Education and Teaching International, vol. 40, no. 2, pp. 112-122, 2003.

[18] P. Ovens, "A patchwork text approach to assessment in teacher education," Teaching in Higher Education, vol. 8, no. 40, pp. 5455562, 2003.

[19] K. H. K. Tan, Alternative Assessment in Schools: A Qualitative Approach, Pearson Education South East Asia, Singapore, 2nd edition, 2011.

[20] K. H. K. Tan and K. Koh, Authentic Assessment in Schools, Pearson Education South East Asia, Singapore, 2008.

[21] I. Vardis, "Effectively feeding forward from one written assessment task to the next," Assessment \& Evaluation in Higher Education, 2012.

[22] V. Trafford and S. Leshem, "Doctorateness as a threshold concept," Innovations in Education and Teaching International, vol. 46, no. 3, pp. 305-316, 2009.

[23] J. H. F. Meyer and R. Land, Threshold Concepts and Troublesome Knowledge: Linkages to Ways of Thinking and Practising Within Disciplines, TLRP/ESRC, Swindon, UK, 2003.

[24] P. Davies and J. Brant, Business, Economics and Enterprise: Teaching School Subjects, Routledge, London, UK, 2006.

[25] D. Boud, "Reframing assessment as if learning were important," in Rethinking Assessment in Higher Education, D. Boud and N. Falchikov, Eds., Routledge, London, UK, 2007. 

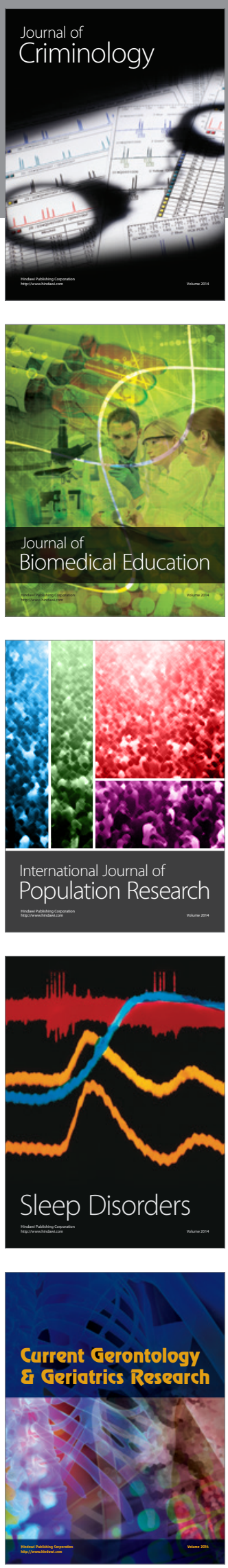
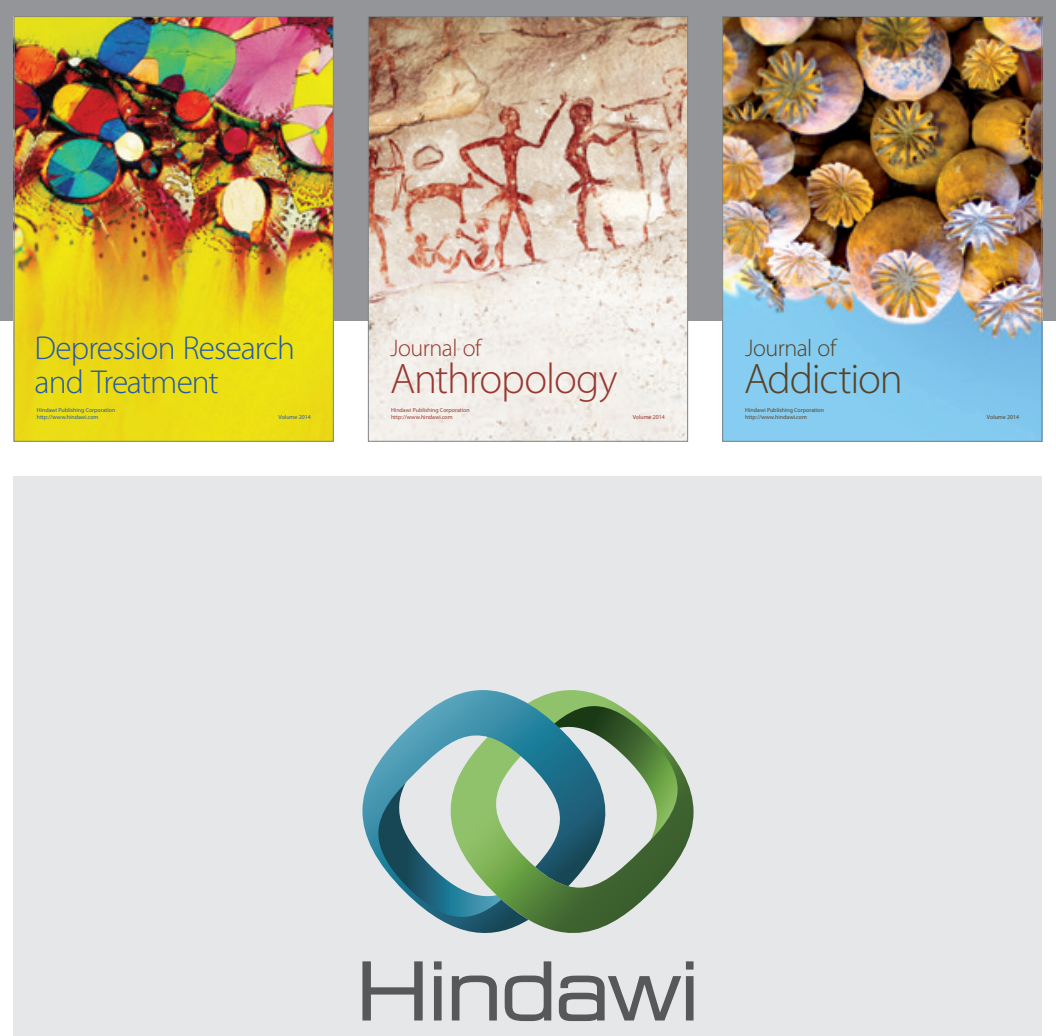

Submit your manuscripts at

http://www.hindawi.com

Child Development Research
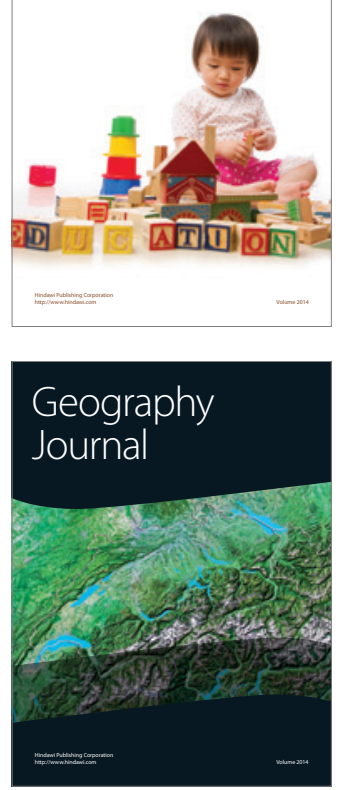

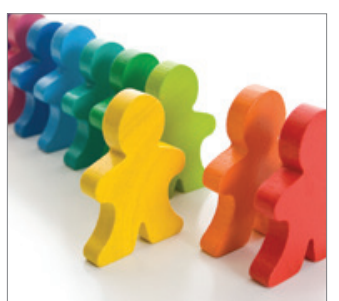

Autism

Research and Treatment
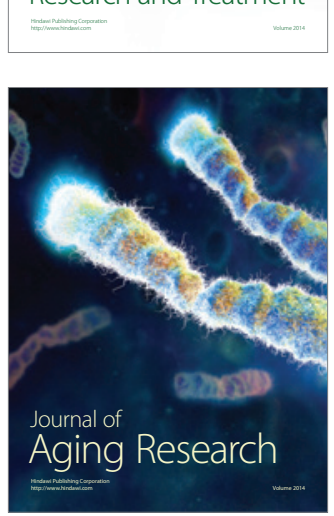
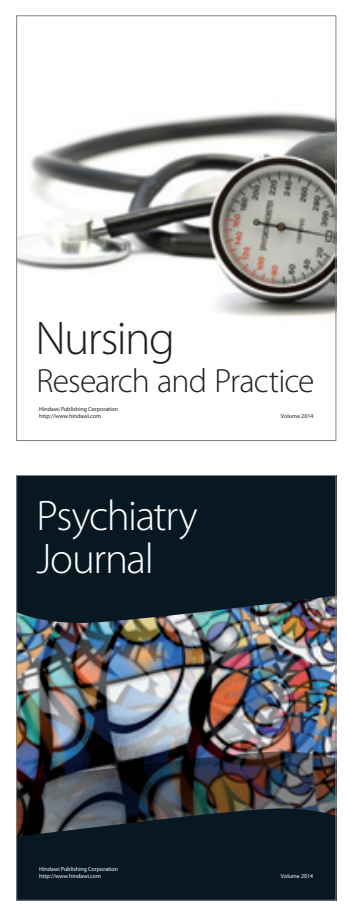
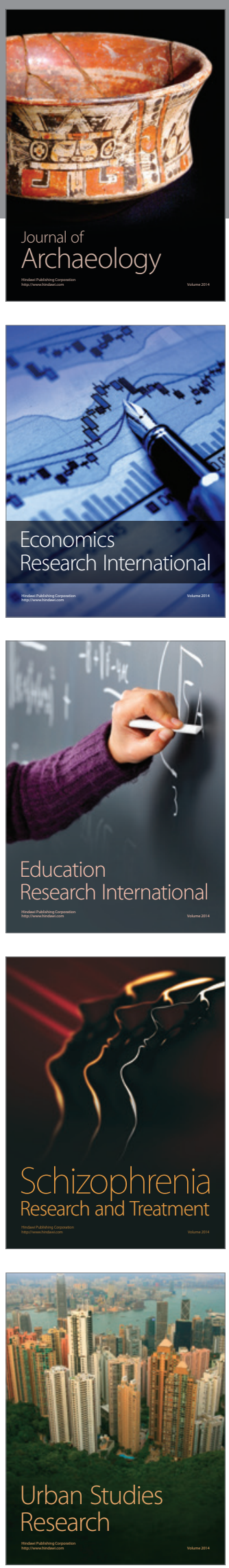